\title{
Understanding housing delays and relocations within a Housing First model
}

\author{
Zerger S., Pridham K.F., Jeyaratnam J., Hwang S.W., O'Campo P., \\ Kohli J., Stergiopoulos V.
}

Version Post-Print/Accepted Manuscript

Citation Zerger, S., Pridham, K.F., Jeyaratnam, J. et al. Understanding housing (published version) delays and relocations within a Housing First model. J Behav Health Serv Res (2016) 43: 38. doi:10.1007/s11414-014-9408-9

Publisher's Statement The final publication is available at Springer via http://dx.doi.org/10.1007/s11414-014-9408-9.

How to cite TSpace items

Always cite the published version, so the author(s) will receive recognition through services that track citation counts, e.g. Scopus. If you need to cite the page number of the TSpace version (original manuscript or accepted manuscript) because you cannot access the published version, then cite the TSpace version in addition to the published version using the permanent URI (handle) found on the record page. 


\section{INTRODUCTION}

Housing First (hereafter HF) is a consumer-driven intervention designed to address recovery needs of chronically homeless persons with psychiatric disabilities. The model differs from traditional approaches because it offers immediate, direct access into independent housing without requiring consumers to meet treatment or other prerequisites proving "housing readiness." Mounting evidence about HF's potential to end chronic homelessness has led to its implementation in a growing number of urban and suburban communities across the United States, Canada, England, and the Netherlands (SAMHSA, 2007).

This rapid dissemination of $\mathrm{HF}$ has resulted in variability in its implementation, with programs adapting and modifying the model to accommodate local contextual factors and resources. (Gaetz, Scott, \& Gulliver, 2013; C. Pearson, Montgomery, \& Locke, 2009). As a result, there is a pressing need to clarify the core principles of $\mathrm{HF}$ and identify strategies that support model fidelity during implementation. (Watson, Orwat, Wagner, Shuman, \& Tolliver, 2013). A recent report on HF in Canada identified the following core principles: immediate access to permanent housing with no housing readiness requirements; consumer choice and self-determination; recovery orientation; individualized and consumer-driven supports; and social and community integration(Gaetz et al., 2013), p.5-6. The recent publication of a HF Fidelity Scale (Gilmer, Stefancic, Sklar, \& Tsemberis, 2013) may address previous concerns "that fidelity to the core principles of Housing First may not be adhered to as it becomes more popular". . In 2008, five Canadian cities embarked on the largest HF implementation study to date - "the At Home/Chez Soi Demonstration Project" In Toronto (one of the five sites), an early an implementation evaluation revealed service providers were experiencing difficulties with two aspects of HF implementation: providing "immediate access" to housing, and responding to an unexpected number of participants requesting transfers after being housed. Some of their anxiety about these issues may have been exacerbated by their awareness of their progress in relation to that in the other study sites. These difficulties inspired the current study, which aims to explore factors underlying housing delays and transfer requests during HF implementation, consumer and service provider 
experiences with them, and strategies developed to address them .

\section{Immediate Housing Placement and Tenure Patterns}

Although immediate, direct access to independent housing is a core principle of the Housing First model, the process for making it happen lacks definition and examination in the published literature. For example, in a comprehensive review of $23 \mathrm{HF}$-identified programs in the U.S., authors reported the widest variation was in the immediacy of placement in a permanent housing unit. While programs expressed a strong commitment to direct placement into permanent housing, the study team identified only two programs actually doing so (C. L. Pearson, Locke, Montgomery, \& Buron, 2007). Authors of a systematic review of outcome studies on HF and other supported housing models found just $40 \%$ met their criteria of "immediate" housing access when defined as the absence of an interim preparatory setting (Tabol, Drebing, \& Rosenheck, 2010). Studies explicitly identifying how much time "immediate" access took are rare and have mixed results. An early study on Pathways to Housing, the pioneer HF program, reported half (52\%) of participants randomized to HF were moved into "some sort of housing" within the first week of enrollment (Tsemberis, Moran, Shinn, Asmussen, \& Shern, 2003). Yet a study of over 600 chronically homeless veterans admitted to the Veterans Affairs Supportive Housing program, which adopts the HF policy, found the average amount of time it took for consumers to be screened, admitted and housed in permanent independent housing was 241 days, with nearly half of the time spent from intake to referral (Tsai, O'Connell, Kasprow, \& Rosenheck, 2011).

Ample literature supports strong housing retention outcomes for consumers once they are engaged in a HF program; for example, the Pathways to Housing program has reported that $80 \%$ or more of consumers stayed enrolled after twelve months (Stefancic \& Tsemberis, 2007; Tsemberis et al., 2003). However, a variety of housing disruptions are expected once consumers acquire permanent housing: as one author put it, "housing stability is an iterative process" (Lipton, Siegel, Hannigan, Samuels, \& Baker, 2000; C. Pearson et al., 2009) (Pearson p.415). For example, many HF consumers spend time in other living environments after initially housed. One study found only half of those enrolled in HF spent every night in their unit during the first year, and another found HF consumers 
were stably housed about $75 \%$ of the time during the final six months of the 4-year study (Padgett, Gulcur, \& Tsemberis, 2006; C. Pearson et al., 2009). A substantial proportion of HF consumers also change housing units/apartments after their initial housing; one study reported estimates ranging from about one-third to three-quarters changed housing within the first twelve months (C. Pearson et al., 2009).

\section{Factors affecting Placement and Stability}

Several factors affect the timing and stability of housing placement. Some common structural factors affecting how rapidly consumers can access housing include housing availability and affordability, funding and income rates, and landlord recruitment and engagement. The type of partnerships with housing providers also affects timing; for example, some programs own or hold the lease to apartments which they rent to consumers, while others have housing partners retain apartments for consumers (Tsai et al., 2011). The effect of consumer characteristics on housing placement and relocations remains largely unexplored. The one known quantitative study that examined effects of consumer characteristics on placement timing concluded that consumer mental health, substance use, employment status/income, and criminal history explained little of the variance in the process time for housing access (Tsai et al., 2011). A study that assessed consumer characteristics' effects on housing tenure patterns found only gender and prior living situation to be significant, with men and individuals recruited directly from the streets to be more likely to experience temporary departures after housing (C. Pearson et al., 2009). A few qualitative studies on consumer experiences with HF have identified "readiness" as a factor affecting timing of placement into housing and engagement with the model. For example, one study described implementing a HF approach with 23 formerly homeless consumers and concluded "pre-engagement readiness to leave the street played a key role" (Jost, Alevitt, \& Porcu, 2010), p.258; another with five formerly homeless persons similarly commented on the need for consumers to be "ready", but acknowledged "limited insight into how such readiness develops” (Parkinson \& Nelson, 2003; C. Pearson et al., 2009; Tsai, Bond, Salyers, Godfrey, \& Davis, 2010; P. Yanos, Barrow, \& Tsemberis, 2004). 
Housing placement and tenure issues are expected in any program targeting people with psychiatric disabilities, but while frontline providers and consumers play key roles in securing and maintaining housing, their voices are conspicuously scarce in the published literature. This study uses qualitative methods to address this gap, and explore: 1) what non-structural factors contribute to undue delays and relocations during implementation of a HF program? And 2) how do service providers and participants experience and respond to these situations? This study then aims to expand our understanding of how HF principles are applied in practice, both to better appreciate the complexities inherent in the implementation process and identify potential strategies to address them..

\section{METHODOLOGY}

This study, conducted at the Centre for Research on Inner City Health at St. Michael's Hospital in Toronto, supplements findings from Toronto's involvement in the At Home/Chez Nois study (hereafter 'At Home'), funded by the Mental Health Commission of Canada to investigate the effectiveness of HF in the Canadian context. Toronto's At Home participants were recruited from a variety of organizations serving people experiencing homelessness; eligibility criteria included being absolutely homeless or precariously housed, being 18 years or older, and having a mental illness as determined by the MINI: Mini-International Neuropsychiatric Interview. (For detailed information about the eligibility criteria, recruitment procedures, and other aspects of the Toronto site of the At Home study, see (Hwang, Stergiopoulos, O'Campo, \& Gozdzik, 2012; Stergiopoulos, 2012). Both At Home and this supplemental study were approved by the Research Ethics Board at St. Michael's Hospital, Toronto.

Study Sample: A total of 48 individuals (23 staff and 25 consumers) participated in this study.

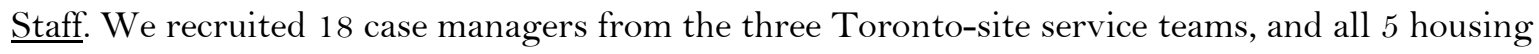
workers, including their managers. Consumers. (see Table 1) Half ( $\mathrm{n}=301$ or $51 \%)$ of Toronto's At Home study participants were randomized into the HF intervention. Of these, most (253 or $84.1 \%$ ) were housed within 120 days of enrollment, 27 (9\%) were housed between 120 and 365 days ('delays'), and 21 
(7\%) continued to be unhoused for one year or longer ('never housed'). Determination of four months as the cutoff for a "delay" is based on the program's goal of housing participants within three months of enrollment. About one-third ( $\mathrm{n}=102$ or $34 \%$ ) of those in the HF intervention had either relocated one or more times after initial placement or had submitted a relocation request ('transfers') at the time of this study. For the current study, we randomly selected and recruited ten participants each from the 'delays' and 'transfers' groups. The researcher made at least three failed contact attempts before selecting the next potential participant on each recruitment list. To recruit participants from the 'never housed' group, we resorted to convenience sampling, but were only able to recruit five individuals because many resisted contact from research or services, had moved out of the city, or had missing contact information. Thus, our final study sample included 25 consumers, all of whom received cash compensation and transportation costs to participate.

Although recruitment of consumers came from three distinct lists, there was significant overlap in their experiences. For example, among the 102 At Home 'transfers' participants, nearly half ( $\mathrm{n}=49$ or $48 \%$ ) also experienced delays in finding first housing, multiple transfers, and/or a period in temporary housing, during the transfer process. In our study sample of 25 consumers, three in the 'delays' group also had at least one transfer, and three in the 'transfers' group had experienced delays in being housed.. Those in the 'delays' and 'never housed' groups had many commonalities. Thus, in our findings section, we describe experiences with delays and transfers generally, only highlighting distinctions when they arise. (Table 1 here)

Data Collection: Data collection occurred between July and November, 2012. Semi-structured qualitative interviews, lasting approximately one hour, were conducted with the 25 consumers, three service team managers, and two housing team managers. We also conducted four focus groups, including three with a total of 15 case managers and one with three housing workers. Analysis: We used thematic analysis to address our study questions. Interviews and focus groups were audio-taped and transcribed. The researcher who conducted all data collection was the primary analyst, which facilitated familiarity with the data, and careful documentation of notes and observations throughout. 
This researcher developed a foundational coding scheme based on the clusters of questions in the interview protocols (e.g. 'housing search process/experience' and 'reasons for delays') and other recurring areas of discussion in consultation with the study's principal investigator. She then coded a sample of transcripts, one from each of the participant categories, using NVivo 9.2 software. A second analyst, not involved in the design or data collection phase of the study, reviewed all study materials which included reading the primary analyst's notes and all interview transcripts, and listening to audio recordings of the focus group sessions. The second analyst then reviewed the codes and discussed emerging themes with the primary analyst. The primary analyst conducted all coding, but the two analysts convened at least once each week to discuss, clarify, and refine emerging themes, and reach consensus when interpretations did not match. This process closely adhered to the phases of thematic analysis, with the overall themes - or "story" of the analysis - becoming increasingly coherent and consistent over time.(Braun \& Clarke, 2006). We assigned ID codes to match participants to quotations throughout the Findings section. Codes were assigned as follows: Team managers (TM...TMO5); Focus Groups (FG01...FG04); Consumers who experienced delays (CDO1...CD10), relocations (CR01...CR10), or were identified as never housed (CNo1...CNO5).

\section{FINDINGS}

\section{Consumer Participant Characteristics (See Table 2)}

As this subsample was drawn from the larger Toronto At Home study, all participants were adults and met the basic eligibility criteria of being absolutely or precariously housed and having a mental illness. Demographic characteristics of this subsample were comparable to those of the larger sample (Hwang et al., 2012). Two-thirds (68\%) of the consumers we interviewed were male, and the average age was 42 years. Nearly half $(n=12$ or $48 \%)$ were born outside Canada, naming six different birth countries. The largest self-identified ethnic groups include White (Canada) (20\%), Black (Canada) (16\%), and South Asian (12\%). A slight majority (60\%) had been homeless for three or more years.

(Table 2 here) 


\section{Factors Affecting Housing Timing and Stability}

We exposed three nonstructural factors that influenced how quickly consumers accessed housing and their stability once housed: effectiveness of communication and collaboration between and among providers and consumers; consumer preferences and ambivalence; and, provider prioritization of consumer choice over immediate access to housing. All of these factors were identified by at least a simple majority of each of the participant groups (case managers, housing workers, and consumers).

\section{Factor 1: Effectiveness of Communication and Collaboration}

Ultimate determinations about which housing was accessed, and how quickly and stably, occurred within multiple conversations between and among housing workers, case managers, and consumers. While these discussions occur within any program implementing $\mathrm{HF}$, formats and configurations may vary significantly. For example, some programs may have housing workers and case managers participating on the same team(s) in-person throughout implementation, while others (including the Toronto teams) may have provider groups working on separate teams and communicating via e-mail or phone. Consumers may engage solely during in-person sessions with case managers or be integrated more broadly in the discussions. Regardless of how they happen, these conversations are key to the housing process: one approach involves housing workers communicating to case managers the housing availability/options and constraints associated with housing placement, which the case manager then conveys to the consumers; the other involves consumers conveying housing preferences to case managers, who then relay them to housing worker(s). The representation (below in Table 3) illustrates these as well as the central role of case managers. Within these pivotal conversations, we found that conflicting priorities and expectations between housing workers and case managers, as well as the perceived strength of the therapeutic alliance between case managers and consumers, affected housing placement timing and stability, and the capacity to minimize potential delays caused by external or structural factors. (Table 3 here)

\section{Conflicting Priorities and Expectations: Housing Workers and Case Managers}

These conversations in Toronto were influenced by inherently divergent perspectives and 
priorities of these provider groups. Housing workers need to understand and comply with market limitations, housing partner policies and directives, and landlord criteria, while case managers focus on consumer needs, preferences, and personal barriers. As one respondent put it, the case managers "by nature are more advocacy based and support based" (FG04) while the housing workers saw themselves as "the voice of reality" (FGO4) in terms of relating housing market and program constraints. These differences persisted regardless of how these groups worked together. For example, at the onset of program implementation in Toronto these groups had conflicting ideas about how consumer choice would be operationalized; case managers aimed to offer the ideal housing match to consumers, while housing workers assumed choice would be restricted to an existing housing inventory list. As long as these expectations and priorities conflicted, housing placement processes were compromised.

Concerns about relaying "unrealistic expectations" (FGO4) and offering "unfettered choice" (TM05) to consumers, as well as ambiguity about fulfilling relocation requests (“[when consumers] have destroyed their units ... the initial project design was ambiguous, like, should there be consequences to that? Should they be immediately transferred?”TMO3) distracted providers from housing efforts. Unclear expectations also led to ineffective collaboration: "we're really all working on the same project and it didn't feel that way"(FGO2); and, "we were kind of working towards the same goal, but we were all so separated.”(FGo3)

Being unable to meet consumer preferences added to frustration and feelings of inadequacyboth for housing workers: "it's like ...you're sort of hitting 90\% or 95\% of what they're looking for, but they have this vision that's not consistent with the housing market"(TMO4); and case managers: "When [consumers] came to us or when we went to see them, those hopes weren't lined up at all with what we were or could deliver as a service ... they had all this hope but there was no way you could deliver."(FGO2)

Therapeutic Alliance: Case Managers and Consumers

Nearly all study participants noted that the quality of the therapeutic alliance between case managers and consumers also affected housing access timing and stability. For example, a consumer 
who trusted the case manager was more likely to believe their reasons for not placing them into housing as rapidly as they had hoped, as this respondent asserts:

“if the worker said I'm really sorry but somebody got that unit before you or we still haven't heard back, they were willing to go on the strength of their relationship... when there is already working relationship of trust, that really helped weather some of those storms."(TMO2) Without trust in the relationship, the consumer may not believe these constraints are real and may not be as open to alternatives, which can delay their placement into housing. This manager described the importance of the alliance between the case manager and consumer in influencing rapidity of placement: "that relationship is key. ... while they're trying to build that trust with that participant, sort of entertaining [their] wishes and dreams...how you do that as a service worker while at the same time trying to move them quickly into housing, is really critical”(TMO5)

This consumer shares his perspective on growing frustration when his case manager was slow to find housing:

"you keep calling him every day, asking the same question - and he will be tired of you, you know? And then you too, you are tired of his answers every day- no, something is coming, wait. There's a little friction.” (CDO6)

The perceived soundness of the therapeutic alliance also influenced whether consumers stayed engaged with services both pre and post- housing placement. For example, some consumers frustrated with delays would begin to shut out their case manager: "sometimes consumers started refusing to meet with the [case manager] and then they would disappear and then it would be this long gap in service;" (TMO2) and, "for the last month or so, he's been non-communicative with the case manager... and with the housing team, because he's, kind of, upset." (TMO3) This consumer, frustrated with the amount of time it was taking for the team to honor her transfer request, commented:”Yeah. I won't even talk to them anymore. I want nothing to do with them." (CD08) Those consumers who remained engaged throughout housing placement were more apt to continue engagement after being housed, as this housing worker comments: 
"if the trust is not there, then those weekly visits that the [case managers] are required to provide to the participants, those weekly visits aren’t going to happen. From our perspective, those are critical. It's important that ... they happen in the housing unit, because that also gives [the case manager] a chance to see what's happening in that unit. It's part of how that individual is transitioning...to, you know, a life of being housed and recovery." (TMO5) Rapidity and stability of housing is influenced by consumers' housing choices, and ultimate determinations of whether/how these choices are met occur within a dialogue between and among consumers, case managers, and housing workers. When housing workers and case managers, who have inherently divergent perspectives and priorities in the placement process, lack a shared understanding of how choice is operationalized and their roles in the process, they are unable to collaborate effectively and efficiently, resulting in preventable delays and transfers. As expected, the therapeutic alliance between case managers and consumers affects how consumer preferences are relayed and understood, how disappointing news about constraints are received, and the level of engagement after housing.

\section{Factor 2: Consumer Preferences and Ambivalence}

\section{$\underline{\text { Consumer Preferences }}$}

Consumer preferences affected how quickly and satisfactorily they accessed housing. Most consumers experiencing delays had clear preferences, usually location-related, and were willing to wait even if the amount of time was frustrating to them or their case managers:

"Because [the case manager $]$ say $[\mathrm{s}]$ if I want, like, far from downtown... we can get a house for me very fast. And I say no I want to stay in this area. I don't care if it take a little bit longer.”

"The offer was there but I didn't want it. I was willing to wait...location's important. If I'm going to set up roots I might as well set them up where I want to be, not, you know, half way across town." (CNO5)

Though other reasons for rejecting options varied, ranging from a desire to live on a higher floor ("I said I'm looking for a high floor. Much better for...more security" CDO3) to feeling "bad vibes" (CDO2) 
about a building, consumers often defended their decisions in terms of their own safety and recovery:

"I kind of told him what I wanted and that was it. Don't bug me with nothing that I don't want. [response to one she visited:] It's a high drug area and I'm clean now and I'm not going to put myself in a situation where I'm going to end up using again. Because I wouldn't accept places in very high drug infested areas, because I am not going to leave a crack house to get put into another crack house. And that's how I saw it. I'm not going to leave one shitty situation and put myself in another one. There's no use. There would be no sense in moving." (CDo8)

Case managers in each of the focus groups echoed these perspectives: "I mean, we have a few people who focus on one apartment and they don't want to look at anything else;" (FG03) and, "He was very specific about where he wanted to be because he didn't want to move once he was housed." (FG02) "He picked one building and... he said, you know what? I'm cool with waiting, if I can get in that building, I know my life will be good, my health, my connection to my family." (FG04)

Many consumers wished they had waited for their optimal choice, but had instead settled for the first housing option they were given out of fear they would miss their chance to be housed and/or because their current living situation was unbearable. Several of them subsequently made transfer requests and experienced delays while finding their second housing: "so the main thing is that you want somewhere to live and you get it. It didn't matter at that time where I want to go, you know...it's that I want somewhere to live; (CNO4)" and, "I was afraid that they wouldn't give me a place if I was too picky about a place. But that's the state of mind I was in back then." (CRO5)

\section{$\underline{\text { Ambivalence }}$}

Several consumers experienced delays due to ambivalence about choosing or signing a lease on housing. This woman, for example, preferred a short-term lease:

"Short-term. Because a year, I'm not sure I can live or not. People usually stay in a place, maybe, like, a year, two year, that, that's normally. But me, I think half year I have to just try to, you know, [work] hard to keep it.” (CNo2)

When asked why she thought her placement took so long, she remarked "The big reason is, I think, is 
maybe myself. ... I just don't want to fill out the agreement or the lease.” (CNO2) Another man shared his struggles to commit: “it was hard to pick because, you know, you don't know what you're getting yourself into. It wasn't due to housing or anything, because there was a lot of places. Just...it's just me.” (CRO4)

Case managers, too, talked about consumer fears leading to delays: "fear of being on their own... being responsible and all that" (FG03); and "the idea of actually getting housed was scary for some people. I think some people had ambivalence. Some people were actually able to voice 'I could be lonely if I move in, I don't know if I can handle it'." (TMO2) Others described how overwhelming the selection process could be for consumers, "especially for people who have been homeless for years...when you show them so many choices they are very confused, and they don't know exactly what they want.” (FG03)

Case managers and housing workers also attributed some consumer "delay tactics" to ambivalence. For example, they perceived some consumers were deliberately articulating choices that were impossible to achieve: "So in some cases choice can be maybe another sign of ambivalence... it can become impossible for us to find what it is that they want;" (FG01) and, "there's always the few, you know, that we showed 45 units to or whatever...they're just not going to take anything, there's nothing you can do." (TMO4) Other delay tactics included missed appointments and being unavailable:

"we definitely have seen ambivalence from consumers. So that would show up by maybe the consumer disappearing on us, not making the appointments, our meetings. ... we've had a lot of, you know, no-shows for viewings. Another way it would show up.. is that they would want to see a whole lot of apartments so they would like that one but they still want to see another one and they want to see another one. That starts to look like a delay tactic, there's some fear." (TMO1)

Consumers, case managers, and housing workers all concurred that consumer preferences and ambivalences about housing led to delays and transfer requests; others who made hasty decisions about their initial placements out of fear of losing a housing opportunity altogether also experienced delays 
after requesting transfers for preferred choices.

\section{Factor 3: Providers Prioritizing Choice over Immediate Placement}

For these consumers who struggled the most with obtaining and/or maintaining housing, case managers felt caught between two competing HF mandates: to respect consumers' housing preferences and to facilitate rapid access into independent housing. In these situations, they universally opted for choice, which led to delays and transfer requests.

Both case managers and housing workers contributed to delays and relocation requests when they supported consumers' expressed preferences or ambivalence about committing to housing to take precedence, even when it meant "bad stats" for immediate housing access:

"I'm sure I could have housed some of my consumers faster if I just had gone and said okay, pressure them to take whatever is available on the list but I tried to - and I think we all do respect what their wants were.” (FGO2)

They consistently defended their adherence to choice in terms of housing retention and long-term engagement: "it took him a long time and he stayed in the shelter system until he got what he wanted and it worked out for him. He's still there;" (FGo2) and, "I think she had in her mind the 'dream place' and she just couldn't accept anything other than that and we found it and she's still successfully housed in the same unit." (TMO2) These staff essentially called into question the idea of measuring success for these consumers in terms of rapid placement:

"Well, you know I think it's not all bad, the delays. I think the only thing I would add is that if the delay was caused because the consumer really wanted a unit they were really proud and happy with, then I think it aided in housing retention.” (TMO2)

"I mean, it's a choice-based housing program so you figure when people are given a bit more choice instead of just being told where to go that their first housing, it's going to be somewhat more successful, which we've found, and I mean in some cases it may take a bit longer but if it takes a bit longer and you have a longer successful tenancy, I think that's kind of more important." (FG04) 
Case managers also talked about transfer requests in terms of consumers' recovery. When case managers initiated a transfer as eviction prevention after a consumer caused damage or failed to pay the rent, for example, they described it as an opportunity to address underlying threats to housing stability: "Really what you want to do is minimize the impact to the landlord so that hopefully you can reuse the unit, address the underlying issues with the consumer so that their next housing is more successful and move on." (TMO4) One case manager noted,

"It often works out that with the move comes a conversation about how is it going to go differently this time, you know, because people don't want to have to move and it becomes a lesson for people to be able to figure out how to be better tenants to maintain the housing. So often moving into the second unit has been enough and they're able to do very well in the second unit." (TMO1)

Some consumers not at risk of eviction also made requests for transfers, and case managers again interpreted these as signs of progress: "almost like a graduation." (FGo2) One case manager reflected that one consumer: "was able to come to some conclusions about his wants and needs and what would make him happy." (FG02) Another described a consumer moving out of his initial unit:

"it was really in bad shape...but also in the area that he never wanted to be in....but out of desperation that's where he went. [After] moving into a completely different area ... immediately there was just such a different feel about this apartment. [He took] the initiative to turn it into his home and very quickly, you know, painted the whole place and like really it was just so amazing to see in a very, very short period of time. He's a different person.” (FG02) This housing worker commented about this situation more generally:

"I'm glad we're differentiating here because not all transfers are the result of something bad...Some transfers just simply are the result of, 'All right. I've been in this unit for, you know, six, eight months now. And it's not the ideal location for me and I'd like to transfer if it's possible.' And so we engage in that. And that's not a bad thing. I mean, that's just somebody, you know, experiencing life and saying, ‘This just doesn't work for me.” (TM05) 
Consumer descriptions of their transfer requests echoed these: "it was a chance for me to move forward and progress;"(CRO2) and, "I decided that I'm not travelling with trouble. I don't like the area that I'm in anymore."(CRO9) One consumer talked about his initial placement as "just a house on my path with...well, recovery, right?" and wanting to move because it was becoming more difficult to live in a place "surrounded by a lot of violence and... a lot of drugs, and just unsavory characters." (CRO8)

When consumers experienced long delays, or periods of living in a disagreeable interim housing option due to their own preferences or fears, they generally did not blame their providers. This woman commented on how important it was for her that her case manager respected her preferences: “She don’t get frustrated. She don't give up. You know what I mean? She's just still there... She tells me all the time, 'Whatever decision you make, I support it.' You know? And that's what I need.” (CRO4) This man talked about his case manager respecting his choice to wait for a place downtown: “at least they didn't rush me into taking the first place that I saw. So it was good that they let me pick my own place and not rush me into anything that I didn't want." (CDO1)

When these HF mandates - supporting housing choice and facilitating immediate placements into independent housing -conflicted with each other, providers prioritized choice, which contributed to delays and transfer requests. All three groups - consumers, case managers, and housing workers described these delays and transfer requests in terms of the consumers' long-term recovery.

\section{Strategies Employed to Improve Housing Placement and Tenure Strategy 1: Consumer Engagement in Housing Searches}

From the onset of implementation, a strategy employed by the Toronto project team to engage consumers and ensure their choices were met was to encourage their participation in the housing search process. Interested consumers took the initiative to seek out initial or relocation housing options on their own by searching want ads or websites, and either giving their case manager the contact information or following-up themselves. Housing workers embraced this option: "they would find places on their own which in theory is great," (FG04) as did case managers: "the upside was it gave us a chance to bond a little differently with the consumers...I mean, god, the number of counseling sessions we had 
in the front seat of my car." (FGo2) Consumers endorsed this approach: "I thought we should have more [involvement in] the apartment looking, like we should have had more to do with it as opposed to them already having picked apartments"(CDO8); and, "I took it on myself to like, put some work in, at least and show them that I was... serious about moving."(CRo8)

Some of these efforts contributed to better and/or quicker housing placements, but they also generated frustration when consumers brought information about units not meeting pre-established quality criteria for approval: "it could be a huge time consuming process ...it's great while they may take initiatives to find places but the places that they found weren't always move-in ready, you know."

All three parties agreed that consumers should have the opportunity to participate in their own housing searches, and for some it meant expedited access and/or an optimal housing match. But the strategy also increased work for already-strapped case managers and housing workers, so it unexpectedly created delays and frustrations in their efforts to locate appropriate housing.

\section{Strategy 2: Structured Communication}

Structured, focused communication between the provider groups vastly improved their ability to collaborate on their shared goal of placing consumers. Although both provider groups communicated frequently by phone and e-mail, it was not until case management and housing team managers began to hold regular conference call meetings specifically to strategize about the "hardest to house" consumers, and when housing workers began to meet face-to-face with case managers, that they began to feel their respective roles and constraints were understood and respected. These housing workers talked about how this shifted perceptions: "I was able to get a window into the world of the participants or the service teams to sort of see what their troubles were and learn a little bit more about the agencies" (FG04);and, "they could see how hard we worked to get their consumers housed, and what we did to successfully keep them." (FGO4) Case managers also spoke to this: "it was clear very quickly that they were coming from a different perspective than the perspective that we needed to be coming from in terms of dealing with our participants on a day in and day out basis."(FG02) Benefits from these meetings were also extended to consumers: "We eventually got one of the [housing workers] to come 
to a peer support group, to speak to the consumers. Just so we could... get on the same page as everybody, to get some clarification."(FG03)

When communications improved and engendered trust between the two provider groups, they were able to focus more directly on understanding individual consumers' "true" priorities and streamline their efforts. This housing worker described trying to house a woman who wanted to live in a specific location "because that's what she knew", but where there was no availability:

"So it became really challenging. There was literally nothing around there for us to find for her. ... so then you have to start to have conversations with the service teams around what it is about [this location] that's drawing this participant there? Are there other neighbourhoods or other places in the city where we could recreate that for that person? And we did that for a lot of people because sometimes the choices were so difficult that we were just unable to achieve them. We had to sort of start thinking outside of the box."(FG04)

The provider groups began to share details about especially complex individual consumer situations: "we started to be able to have dialogue and as the trust sort of opened ... just even [to be able to] talk about some of the stuff that was going on for a person so that we could find something that would work" (FG04); and, "the more that we know, the easier it is for everyone to kind of do their jobs and do their work. ...I think they started to realize that having real conversations with us about a participant actually helped us find them housing more easily." (FGo4) In especially difficult cases, housing workers met and corresponded directly with consumers:

"we were working in different pockets but then at some point we had [housing workers] get more involved and get to know our consumers, get to do visits when there were problems and kind of get to know the consumers and so [improved] problem-solving." (FG01)

Structured, targeted, and in-person communication enabled shared understanding and trust; providers were able to customize housing placement efforts and to successfully engage consumers throughout housing placement and post-placement. All groups collaborated more creatively and responsively to overcome external constraints and thus minimized preventable housing delays and 
requests for transfers.

\section{DISCUSSION}

Ensuring direct access to permanent independent housing is a core principle of the HF model, and housing stability and retention are key outcomes, yet the processes for achieving these are not clearly and consistently described in the literature. With rapid dissemination of $\mathrm{HF}$ in various service contexts, a better understanding of the process of accessing and maintaining housing can guide implementation strategies and support model fidelity, even in the context of local adaptations to address structural and resource constraints. . For example, communities with very limited housing stock tend to retain the HF philosophy by stressing the directness (i.e. no housing readiness requirements) of placement into housing more than "immediacy" (C. L. Pearson et al., 2007; Tabol et al., 2010). Consumers, case managers and housing workers ultimately determine which- and how rapidly - housing is accessed and how much housing stability consumers experience, yet their voices have been rarely heard in the published literature. This study aimed to explore provider and consumer perspectives of their experiences and responses to challenges in finding and keeping housing of their choice. We identified three nonstructural factors contributing to housing delays and relocations: 1) the effectiveness of "choice" conversations occurring between and among these three parties where ultimate determinations about choice and housing occur; 2) consumer-driven preferences and ambivalence; and, 3) provider prioritization of consumer choice over immediate access to housing. We also identified two strategies that affected timing of housing and housing stability: 1) consumer engagement in housing searches, and 2) structured communications.

Our findings support previous research which asserts the importance of "housing choice" to the HF model and exposes some of its complexities. Consumer choice is universally understood as important and its merits well-documented, including a range of positive outcomes such as reduced psychiatric symptomatology, and increased residential stability and social integration (Greenwood, Schaefer-McDaniel, Winkel, \& Tsemberis, 2005; Gulcur, Tsemberis, Stefancic, \& Greenwood, 2007; Nelson, Sylvestre, Aubry, George, \& Trainor, 2007; O'Connell, Rosenheck, Kasprow, \& Frisman, 2006; 
Padgett et al., 2006; Srebnik, Livingston, Gordon, \& King, 1995). Yet systematic reviews of HF programs have cautioned that its effects on outcomes are mixed and "very complex" and its operationalization variable and "lacking specificity" (Johnsen \& Teixeira, 2010; C. Pearson et al., 2009; C. L. Pearson et al., 2007; Tabol et al., 2010). In Toronto, all parties involved in the implementation of 'At Home' wanted to maximize consumer choice in housing characteristics and location, but reaching a shared understanding of how choice should be addressed, within market constraints and inherently divergent perspectives of housing workers and case managers, proved more complicated and timeconsuming than anticipated. A clear, agreed-upon protocol from the beginning would have helped navigate these difficulties. Indeed, once the two provider groups worked out a protocol, agreed on common goals, and learned and respected each other's work contexts, roles and barriers, they were able to be more flexible and effective in their housing efforts. Clear communication with consumers in both setting and managing housing expectations as well as consumer empowerment to engage in housing searches were also valued approaches. . Clear communication between these stakeholders groups enabled them to shift from a focus on providing breadth of choices to consumers to a more nuanced understanding of the consumers' “true priorities.” This supports Schutt and Goldfinger's recommendation to assess how consumers understand their own needs rather than their list of wants (Schutt \& Goldfinger, 2009). Structuring focused communication opportunities between housing workers, case managers, and consumers further built trust among the groups and enabled sharing information about consumers so searches could be customized for those experiencing challenges; a stronger perceived therapeutic alliance between case managers and consumers meant the latter were more likely to believe 'bad news' about housing availability and to engage with the case manager prior, during and after housing placement.

All three parties concurred that adherence to consumer choice was a key contributor to housing delays and transfers, and defended it in terms of long-term recovery. For example, some consumers expressed clear desires to wait for a location in a neighborhood with less drug activity or one close to their family, because they knew it would be best for their recovery and result in better housing stability. 
Waiting was often frustrating and difficult, but these consumers had a clear understanding of their own needs, saw themselves as the ones in control of the decision and did not implicate their workers. The case managers (and the housing workers, to the extent they were involved) saw their respect for consumer choices to delay housing as important for consumers' trust and ongoing engagement with services. They interpreted housing transfers resulting from property damage or failure to comply with tenancy expectations as eviction prevention, and a critical learning opportunity for understanding consumer's issues and barriers to maintaining stable housing. Both providers and consumers described transfers that were not eviction-prevention as a "graduation" of sorts - signs of progress in selfawareness and recovery. When the principles of 'housing choice' and 'immediate placement' conflicted, choice prevailed - notably the principle most determined by a consumer-driven approach and tied to long-term recovery outcomes. This tendency supports previous findings that case managers with "good therapeutic alliances" and shared decision-making with consumers resulted in longer-term engagement, and supports the need to better understand consumer and provider perspectives (Tsai et al., 2011). There are potential implications to the HF model when consumer choice takes precedence over immediate placement into housing; for example, the availability of appropriate interim housing became more important than originally anticipated. It also suggests the importance of nuance in measuring fidelity to the principle of immediate placement, since some slower placements into permanent housing may not reflect violation of the model but rather adherence to consumer preferences.

This study raises interesting questions about the role of "ambivalence" for housing within the HF model. As noted previously, the few qualitative studies which have explored consumers' hesitations to engage with the HF model have concluded that consumer 'readiness' to leave the street and/or sign an apartment lease played a key role. Our findings support prior research as well as add provider perspectives: consumers, case managers and housing workers all agreed that for these consumers experiencing long delays or requesting multiple transfers, choices and ambiguity about living in and/or committing to independent housing led to placement delays. Several of the consumers who experienced delays expressed clear preferences to wait for their ideal choices, others articulated their ambiguity (e.g. 
being overwhelmed or afraid), and others, according to providers, employed delay tactics like repeatedly missing appointments or asserting unrealistic choices. The consumers who requested housing transfers, on the other hand, tended to have made a hasty initial choice and expressed (or realized) preferences which created delays later in the process. In all of these cases, delays were consumer-, not model-driven. That is, these issues related to 'readiness' within HF are distinct from traditional 'housing readiness' models which require consumers to meet treatment adherence or sobriety prerequisites before being deemed eligible for housing. Within HF, embracing a consumer-driven approach can mean providers support consumers choices for housing - and working with their 'ambiguousness' - though continuous service engagement and motivational interviewing to support consumers' housing and recovery goals.-

Our findings also raise questions about consumer characteristics associated with the timing of housing placement. As noted earlier, one study which assessed this issue found consumer characteristics and histories had little impact on how quickly consumers were placed into independent housing (Tsai et al., 2011). The present study largely upheld this finding for consumers experiencing long delays and/or requesting multiple transfers, as issues related to choice appeared to play a predominant role. However, two of the five "never-housed" consumers experienced long delays due to lack of personal identification, an unforeseen barrier worth consideration in future research. And while about half (48\%) of our study participants were ethnoracial and foreign-born, specific issues around culture or race in housing choice did not emerge in our findings. Reasons for this may include that our interviewer's status as a white Canadian-born woman may have influenced participants' comfort level with raising issues related to race or culture; and, our sample size was insufficient to reveal themes associated with specific races or cultures (e.g. Chinese vs. Somalian). One other HF study found race/ethnicity played a role in consumers feelings of "fitting in" to neighborhoods, but is not directly comparable as the sample included only U.S-born Blacks and Hispanics (P. T. Yanos, Felton, Tsemberis, \& Frye, 2007).The role and impact - if any - of race and immigrant status in choosing, accessing and maintaining housing in the HF model is an area that warrants further investigation.

In Toronto, providers and consumers endorsed empowering consumers to participate in their 
own housing searches, and some consumers experienced better housing matches more quickly as a result. But because it also generated frustration and more work for providers, it contributed to delays and enthusiasm for the strategy waned. Nevertheless, it showed promise and may be a powerful addition to HF implementation efforts if integrated properly.

This study had several limitations. Our sample was tailored to our research questions, which focused solely on issues related to HF implementation in Toronto, and therefore precludes generalizations. And, while even convenience recruitment of consumers in the "never housed" category was especially onerous, we only interviewed five and those were unlikely to represent "typical" issues faced by others never housed. Nevertheless, our study has raised important questions worthy of future research on the implementation of the HF model. Several years ago, Robbins et al. posed the question whether HF, "which do[es] not require the receipt of treatment as a condition, [could] lead in general to less perceived coercion and enhanced autonomy? If so, will that have an independent impact on treatment responsiveness...? (Robbins, Petrila, LeMelle, \& Monahan, 2006), p.235. This study suggests that we may need a greater understanding of the roles that service providers play, and how best to support them in respecting consumer-driven choicesand, prioritizing thetherapeutic alliance even when choice results in delays in accessing housing and housing disruptions. 


\section{REFERENCES}

Braun, V., \& Clarke, V. (2006). Using thematic analysis in psychology. Qualitative Research in Psychology, $3,77-101$.

Gaetz, S., Scott, F., \& Gulliver, T. e. (2013). Housing First in Canada: Supporting communities to end homelessness

Gilmer, T. P., Stefancic, A., Sklar, M., \& Tsemberis, S. (2013). Development and validation of a Housing First fidelity survey. Psychiatric Services, 64(9), 911-914.

Greenwood, R. M., Schaefer-McDaniel, N. J., Winkel, G., \& Tsemberis, S. J. (2005). Decreasing psychiatric symptoms by increasing choice in services for adults with histories of homelessness. American Journal of Community Psychology, 36(3-4), 223-238.

Gulcur, L., Tsemberis, S. J., Stefancic, A., \& Greenwood, R. M. (2007). Community integration of adults with psychiatric disabilities and histories of homelessness. Community Mental Health Journal, 43(3), 211-228.

Hwang, S., Stergiopoulos, V., O'Campo, P., \& Gozdzik, A. (2012). Ending homelessness among people with mental illness: The At Home/Chez Soi randomized trial of a Housing First intervention in Toronto. BMC Public Health, 12, 787.

Johnsen, S., \& Teixeira, L. (2010). Staircases, elevators, and cycles of change: 'Housing First' and other housing models for homeless people with complex support needs. London: University of York.

Jost, J., Alevitt, A., \& Porcu, L. (2010). Street to Home: The Experiences of long-term unsheltered homeless individuals in an outreach and housing placement program. Qualitative Social Work, 10(2), 244-263.

Lipton, F. R., Siegel, C., Hannigan, A., Samuels, J., \& Baker, S. (2000). Tenure in Supportive Housing for Homeless Persons with Severe Mental Illness. Psychiatric Services, 51(4), 479-486.

Nelson, G., Sylvestre, J., Aubry, T., George, L., \& Trainor, J. (2007). Housing choice and control, housing quality, and control over professional support as contributors to the subjective quality of life and community adaptation of people with severe mental illness. Administration and Policy in Mental Health and Mental Health Services Research, 34(2), 89-100.

O'Connell, M., Rosenheck, R., Kasprow, W., \& Frisman, L. (2006). An examination of fulfilled housing preferences and quality of life among homeless persons with mental illness and/or substance use disorders. The Journal of Behavioral Health Services and Research, 33(3), 354-365.

Padgett, D., Gulcur, L., \& Tsemberis, S. (2006). Housing First services for people who are homeless with co-occurring serious mental illness and substance abuse. Research on Social Work Practice, 16(1), 74-83.

Parkinson, S., \& Nelson, G. (2003). Consumer/survivor stories of empowerment and recovery in the context of supported housing. International Journal of Psychosocial Rehabilitation, 7, 103-118.

Pearson, C., Montgomery, A. E., \& Locke, G. (2009). Housing stability among homeless individuals with serious mental illness participating in Housing First programs. Journal of Community Psychology, 37(3), 404-417.

Pearson, C. L., Locke, G., Montgomery, A. E., \& Buron, L. (2007). The applicability of Housing First models to homeless persons with serious mental illness: Final report. Washington, D.C.: U.S. Department of Housing and Urban Development.

Robbins, P. C., Petrila, J., LeMelle, S., \& Monahan, J. (2006). The use of housing as leverage to increase adherence to psychiatric treatment in the community. Administration and Policy in Mental Health and Mental Health Services Research, 33(2), 226-236.

SAMHSA. (2007). National registry of evidence-based programs and practices: Pathways' Housing First program. 
Schutt, R., \& Goldfinger, S. (2009). Fundamental causes of housing loss among persons diagnosed with serious and persistent mental Illness: A theoretically guided test. Asian Journal of Psychiatry, 2(4), 132-148.

Srebnik, D., Livingston, J., Gordon, L., \& King, D. (1995). Housing choice and community success for individuals with serious and persistent mental illness. Community Mental Health Journal, 31(2), 139-152.

Stefancic, A., \& Tsemberis, S. (2007). Housing First for long-term shelter dwellers with psychiatric disabilities in a suburban county: A four-year study of housing access and retention. Journal of Primary Prevention, 28, 265-279.

Stergiopoulos, V. (2012). Moving from rhetoric to reality: adapting Housing First for homeless individuals with mental illness from ethno-racial groups. BMC Health Services Research, 12, 345.

Tabol, C., Drebing, C., \& Rosenheck, R. (2010). Studies of "supported" and "supportive" housing: A comprehensive review of model descriptions and measurement. Evaluation and Program Planning, 33(4), 446-456.

Tsai, J., Bond, G. R., Salyers, M. P., Godfrey, J. L., \& Davis, K. E. (2010). Housing preferences and choices among adults with mental illness and substsance use disorders: a qualitative study. Community Mental Health Journal, 46, 381-388.

Tsai, J., O'Connell, M., Kasprow, W., \& Rosenheck, R. (2011). Factors related to rapidity of housing placement in housing and urban development - Department of Veterans Affairs Supportive Housing Programs of 1990s. Journal of Rehabilitation Research and Development, 48(7), 755762.

Tsemberis, S. J., Moran, L., Shinn, M., Asmussen, S. M., \& Shern, D. L. (2003). Consumer preference programs for individuals who are homeless and have psychiatric disabilities: a drop-in center and a supported housing program. American Journal of Community Psychology, 32(3/4), 305317.

Watson, D. P., Orwat, J., Wagner, D. E., Shuman, V., \& Tolliver, R. (2013). The housing first model (HFM) fidelity index: designing and testing a tool for measuring integrity of housing programs that serve active substance users. Substance Abuse Treatment, Prevention, and Policy, 8(1-16).

Yanos, P., Barrow, S., \& Tsemberis, S. (2004). Community integration in the early phase of housing among homeless persons diagnosed with severe mental illness: successes and challenges. Community Mental Health Journal, 40(2), 133-150.

Yanos, P. T., Felton, B. J., Tsemberis, S., \& Frye, V. A. (2007). Exploring the role of housing type, neighborhood characteristics, and lifestyle factors in the community integration of formerly homeless persons diagnosed with mental illness. Journal of Mental Health, 16(6), 703-717. 
Table 1

\begin{tabular}{|l|cr|r|}
\hline \multicolumn{1}{|c|}{ STUDY SAMPLES } \\
\hline \multicolumn{1}{|c|}{ Placement Category } & \multicolumn{2}{c|}{$\begin{array}{c}\text { Eligible Participants } \\
\text { (N=301) }\end{array}$} & $\begin{array}{c}\text { Sample Participants } \\
\text { (N=25) }\end{array}$ \\
\hline \hline$\leq 4$ months & 253 & $84.1 \%$ & -- \\
4 months - 1 year ('Delays') & 27 & $9.0 \%$ & 10 \\
$\geq 1$ year or never housed ('Never Housed') & 21 & $7.0 \%$ & 5 \\
\hline \hline 1 or more relocation requests ('Transfers') & 102 & $33.9 \%$ & 10 \\
\hline
\end{tabular}


Table 2

\begin{tabular}{|c|c|c|}
\hline \multicolumn{3}{|c|}{$\begin{array}{l}\text { CONSUMER PARTICIPANT CHARACTERISTICS } \\
\qquad(\mathrm{N}=25)\end{array}$} \\
\hline & $\bar{n}$ & $\%$ \\
\hline \multicolumn{3}{|l|}{ Gender } \\
\hline Male & 17 & $68 \%$ \\
\hline Female & 8 & $32 \%$ \\
\hline \multicolumn{3}{|l|}{ Country of Birth } \\
\hline Canada-Born & 13 & $52 \%$ \\
\hline Foreign-Born* & 12 & $48 \%$ \\
\hline \multicolumn{3}{|l|}{ Age } \\
\hline Range & \multicolumn{2}{|c|}{$22-68$ years } \\
\hline Average & \multicolumn{2}{|c|}{41.8 years } \\
\hline \multicolumn{3}{|c|}{ Homelessness: Lifetime Duration } \\
\hline$<3$ years & 10 & $40 \%$ \\
\hline$\geq 3$ years & 15 & $60 \%$ \\
\hline
\end{tabular}

* This includes individuals from Iran, Sri Lanka, Jamaica, India, Somalia, and China 
Table 3

\begin{tabular}{|c|}
\hline Housing Choice: Availability and \\
Constraints \\
Housing Worker \\
$\downarrow_{\uparrow}$ \\
Case Manager \\
$\downarrow \uparrow$ \\
Consumer \\
\\
Housing Choice: Needs and Preferences
\end{tabular}

